\title{
Potential of circular economy implementation in the mechatronics industry: An
} exploratory research

\author{
Chouinard, Ugo; Pigosso, Daniela C. A. ; McAloone, Tim C.; Baron, Luc; Achiche, Sofiane
}

Published in:

Journal of Cleaner Production

Link to article, DOI:

10.1016/j.jclepro.2019.118014

Publication date:

2019

Document Version

Peer reviewed version

Link back to DTU Orbit

Citation (APA):

Chouinard, U., Pigosso, D. C. A., McAloone, T. C., Baron, L., \& Achiche, S. (2019). Potential of circular economy implementation in the mechatronics industry: An exploratory research. Journal of Cleaner Production, 239, [118014]. https://doi.org/10.1016/j.jclepro.2019.118014

\section{General rights}

Copyright and moral rights for the publications made accessible in the public portal are retained by the authors and/or other copyright owners and it is a condition of accessing publications that users recognise and abide by the legal requirements associated with these rights.

- Users may download and print one copy of any publication from the public portal for the purpose of private study or research.

- You may not further distribute the material or use it for any profit-making activity or commercial gain

- You may freely distribute the URL identifying the publication in the public portal 


\title{
Potential of Circular Economy implementation in the mechatronics industry: an exploratory research
}

\author{
Ugo Chouinard $^{a^{*}}$, Daniela C.A. Pigosso ${ }^{\mathrm{b}}$, Tim C. McAloone ${ }^{\mathrm{b}}$, Luc Baron ${ }^{\mathrm{a}}$, Sofiane Achiche ${ }^{\mathrm{a}}$ \\ ${ }^{a}$ École Polytechnique de Montréal, Department of Mechanical Engineering, 2900 boul. Édouard-Montpetit, Montréal, \\ Canada, H3T 1J4 \\ b Technical University of Denmark (DTU), Department of Mechanical Engineering, Nils Koppels Allé 404, DK- 2800 \\ Kgs, Lyngby, Denmark \\ *email: ugo.chouinard@polymtl.ca
}

\begin{abstract}
:
This paper investigates the current state of design in the mechatronic industry. First, based on a literature overview, key circular product characteristics are identified, namely modularity and robustness. Then, a survey has been distributed to practicing mechatronic engineers. Based on the survey, it is found that mechatronic systems are currently designed for long-term circular strategies, while the end-of-life is rarely considered. Furthermore, it is found that one issue in designing mechatronic devices is that they are prone to electronics obsolescence, and that safety regulations may prevent to design for circularity. Moreover, it is reported that customers do not currently require circular aspects in the mechatronic products and thus there is no incentive to designs according to circular principles. Finally, the paper discuss on new research ways of improving the circularity aspect of mechatronic devices, such as by facilitating remanufacturing or by using distributed system.
\end{abstract}

Keywords: Circular Economy; Mechatronics; Engineering Design

\section{Introduction}

The world population growth and subsequent increasing resource consumption have brought many people to question the traditional linear economy, where a take-make-dispose process is in place. Hence, the circular economy (CE) is increasingly discussed as a means to decouple economic growth from resource consumption (Ghisellini et al., 2016). Consequently, multiple researchers and organisations have looked into defining the concept of CE. One definition that often comes up is from the Ellen Macarthur Foundation (EMF), which defines a CE as a system that designs out waste, keeps products and materials in use and regenerates natural systems (Ellen MacArthur Foundation, 2018). Alternatively, Blomsma and Brennan (2017) refers to CE as an umbrella concept, which encompasses the activities related to the reduction, reuse, recycling, and cascading of products/components/materials throughout the lifecycle. The CE should thus be seen as trying to keep the value of products as long as possible in the system, either from keeping the products in use or by efficiently recycling or cascading its constituents, and thus reducing waste (Kjaer et al., 2018). It could then be perceived as a means of achieving product sustainability.

However, the circularity of a product goes much beyond the product itself, involving a number of stakeholders, customers and governing bodies (CIRAIG (International Reference Center for the Life Cycle of Products Processes and Services), n.d.). For a product to enable circularity, not only appropriate design has to be carried out, but proper business models need to be developed around it. Moreover, customers/users need to ensure that the elements put in place by companies are used to circulate the product. As a matter of fact, it is reported by SB Insight (2018) that the customers perceive themselves as the major drivers of the CE. For the CE to be viable, it thus relies on 5 major concepts (Sauvé et al., 2016): 
1. Reducing environmental impact of the product;

2. Optimizing resource utilisation, both during the development process, manufacturing and use phases of the products;

3. Developing products that can be reused, remanufactured, recycled, etc.;

4. Using renewable energy during the manufacturing/use phases of the product;

5. Creating new business model to support circularity and encourage customers to participate in the circular economy.

The CE is however not a one-size-fits-all principle. Different industries/domains would require different changes to their design processes to allow circularity. Indeed, a solution in one domain or field might already be implemented in another, or might not be feasible at all.

A widely used type of products are mechatronic devices. Their use spans a large range of applications, from "simple" consumer products such as DVD players, to highly complex and critical subsystems of airplanes. Due to the numerous mechatronic devices currently in use, there is a need to design them in a circular manner. Therefore, this work is targeted specifically at finding the current state of circular design in mechatronic development in order to facilitate the understanding and the implication of a $\mathrm{CE}$ in the mechatronics design.

At first, we give an outlook of mechatronic systems and their design process for completeness purpose. Then, we provide an overview of circular product design principles from the literature. To have a better understanding of the current state in mechatronic development for circularity, we carried out a survey with mechatronic engineers, which is then presented. Finally, we provide some insights about improvement to the design process that could be made to ensure more circular mechatronic products.

\section{Research Aim, Question, and Methodology}

This work aims at having a better picture of the implication of a $\mathrm{CE}$ in the mechatronic product design process: identify which aspects of mechatronics are the most critical for circularity, and guide mechatronic engineers for considering circularity aspects during design. Moreover, we will discuss on the applicability of the circular principles related to product design in mechatronics. In sum, this research is exploratory and provides basic knowledge to the development of design methods and tools to help mechatronic engineers move towards the circular economy. This work is thus based on the following research questions:

- RQ1: Which product properties are necessary for a product to be circular, and how do they apply to mechatronics?

- RQ2: What is the current state of development of circularity in mechatronics, and what are the challenges associated with implementing circularity principles?

- RQ3: What needs to be improved in mechatronic design to have more circular mechatronic products?

To answer the first research question, a literature review of product design in $\mathrm{CE}$ is carried out. The literature is compared as to identify common themes and determine if there are key aspects that ease implementation of circularity properties. The review is solely focussed on the product design aspect of the CE.

Then, a survey has been distributed to mechatronic engineers based on the identified properties to better understand which aspects are currently considered. The survey was distributed through interest groups on social networks (e.g. LinkedIn), and also sent personally to mechatronic engineers. In total, there were 28 
respondents to the survey, all working in the field of mechatronics. Lacking a statistically significant number of respondents, the survey is then analysed in a descriptive manner.

Finally, based on the findings of the survey, different research directions are suggested as to ease implementation of CE in mechatronics. Some properties and design changes that would be more accessible for implementation in mechatronic design are thus discussed.

\section{Mechatronics}

Mechatronic devices integrate aspects of mechanical, software, electrical/electronics and control engineering. They are used in a wide variety of fields (e.g. aerospace, automotive, robotics) and thus often require a high level of functionality. These types of devices are inherently challenging to design due to the multi-domain interactions that exist within the system (Torry-Smith et al., 2014, 2012). Consequently, a lot of effort is invested during the design process for the integration of the multi-domain components and subsystems. Developing methods that would facilitate the mechatronic design process and related decision making is thus an active field of research (Chouinard et al., 2017, 2019a; Mohebbi et al., 2018). The main product-related challenges associated with mechatronic devices and their multi-domain nature can be summarized as such (Torry-Smith et al., 2012):

- Lack of common design language to represent a concept,

- Difficulty in transferring the information between the engineering disciplines,

- Difficulty in assessing the consequences of choice between alternatives.

Furthermore, the development of a mechatronic systems is different from regular products since a large part of the process needs to be spent on the software and on the hardware (electronics) development. For instance, on a purely economical point of view, Lee et al. (2013) reports that in the case of a cleaning robot, the hardware development cost could average $\$ 27 \mathrm{~K}$ while the software development could average over $\$ 78 \mathrm{~K}$. Moreover, a big part of mechatronic devices behavior is based on the software component. An example is one of the modification proposed by Volkswagen after the "Dieselgate" where faulty cars undergoes a software update so they comply with environmental regulation (VW Canada, 2017). This software update can alter the driving performance from throttle response or gear shift behavior (automatic transmission) to increased Diesel Exhaust Fluid consumption. Nevertheless, there is still a tight connection between the software aspect and the rest of the mechatronic system and thus all those aspects need to be considered to achieve optimal integration.

Consequently, to ensure a more streamlined development process, product development in mechatronics will often follow the VDI-2206 V-Design process (Gausemeier and Moehringer, 2002). This design process accounts for the need to concurrently consider all aspects of the mechatronics domains. Indeed, throughout the various stages (conceptual, detailed, production, etc.) it is recommended to follow a System DesignConcurrent Domain Specific-System Integration approach, such as shown in Figure 1. This should then allow the various engineering discipline to be constantly interacting and thus should facilitate the integration of the various engineering domains. Therefore, if design methods and tools are to be developed for enabling circularity in mechatronics, they should be integrated to this V-Design process. 


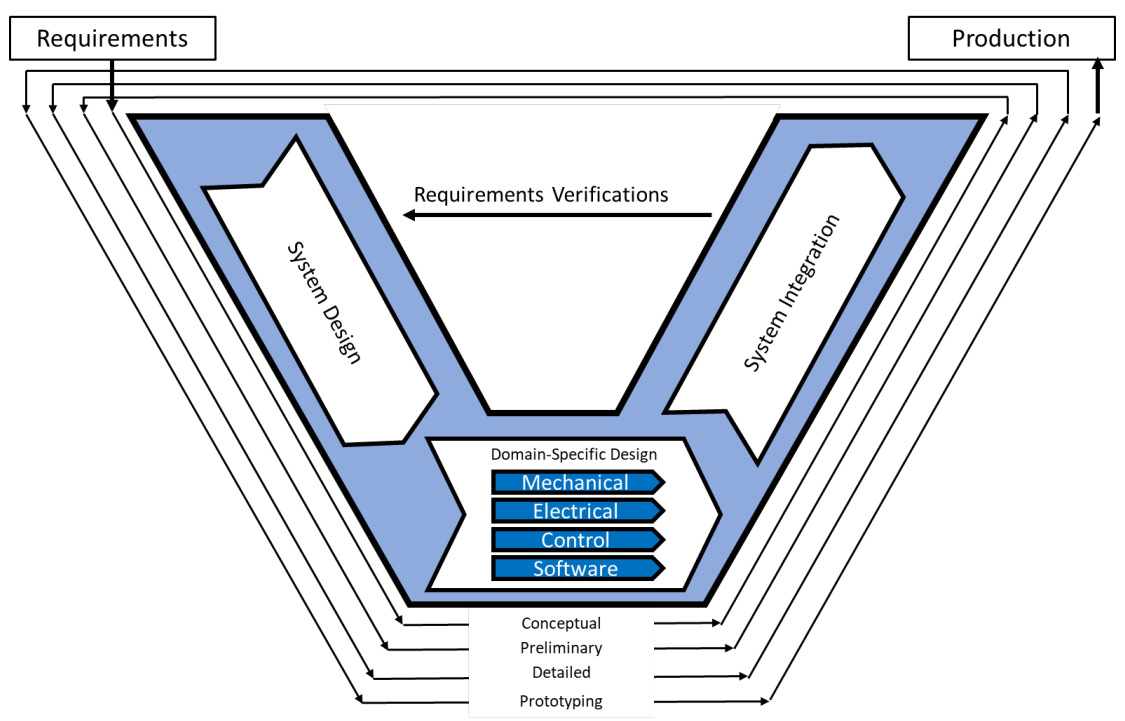

Figure 1: Mechatronic V-Design Process

Moreover, to meet ever changing customer requirements, mechatronic engineers need to design devices that would be working in multiple conditions. If it fails to do so, then the mechatronic device will likely be replaced by a newer more performing or better adapted device. In this work, we consider the properties of mechatronic systems such as outlined by EU-Robotics(2015) and Moulianitis et al. (2018) as being the critical ones that would be subject to result in mechatronic systems to become obsolete. Those properties are defined as abilities by Moulianitis et al. (2018) and are mostly related to the level of functionality of the mechatronic device. We also complete the set of properties with two other that are deemed essential: Safety and Security (Banerjee et al., 2012). Each of these properties would also be related to different mechatronic domains. The full list of properties, with their definition and involved domains (typically) are given in Table 1 . 
Table 1: Mechatronic properties description

\begin{tabular}{|c|c|c|c|}
\hline Property & Definition & Domains involved & References \\
\hline Configurability & $\begin{array}{l}\text { The ability of a system to change } \\
\text { configuration in order to maintain a high } \\
\text { performance level. }\end{array}$ & - All & $\begin{array}{l}\text { (euRobotics } \\
\text { aisbl, 2015; } \\
\text { Moulianitis } \\
\text { et al., 2018) }\end{array}$ \\
\hline Adaptability & $\begin{array}{l}\text { The ability of a system to keep delivering the } \\
\text { same level of functionality by adapting to } \\
\text { changing operating conditions/ environment. }\end{array}$ & - All & $\begin{array}{l}\text { (euRobotics } \\
\text { aisbl, 2015; } \\
\text { Moulianitis } \\
\text { et al., 2018) }\end{array}$ \\
\hline Interaction Ability & $\begin{array}{l}\text { The ability of a system to interact with } \\
\text { humans during operation, to improve the man/ } \\
\text { machine operational skills. }\end{array}$ & - All & $\begin{array}{l}\text { (euRobotics } \\
\text { aisbl, 2015; } \\
\text { Moulianitis } \\
\text { et al., 2018) }\end{array}$ \\
\hline Dependability & $\begin{array}{l}\text { The ability of a system to ensure reliability } \\
\text { and performance integrity. }\end{array}$ & $\begin{array}{l}\text { - } \quad \text { Mechanical } \\
\text { - } \quad \text { Electronics } \\
\end{array}$ & $\begin{array}{l}\text { (euRobotics } \\
\text { aisbl, 2015; } \\
\text { Moulianitis } \\
\text { et al., 2018) }\end{array}$ \\
\hline Motion Ability & $\begin{array}{l}\text { The ability of a system to move in its } \\
\text { operating environment. }\end{array}$ & $\begin{array}{l}\text { - } \text { Mechanical } \\
\text { - } \quad \text { Software } \\
\end{array}$ & $\begin{array}{l}\text { (euRobotics } \\
\text { aisbl, 2015; } \\
\text { Moulianitis } \\
\text { et al., 2018) }\end{array}$ \\
\hline Perception Ability & $\begin{array}{l}\text { The ability to sense the operating } \\
\text { environment. }\end{array}$ & $\begin{array}{l}\text { - } \quad \text { Electronics } \\
\text { - Software }\end{array}$ & $\begin{array}{l}\text { (euRobotics } \\
\text { aisbl, 2015; } \\
\text { Moulianitis } \\
\text { et al., 2018) }\end{array}$ \\
\hline $\begin{array}{l}\text { Decisional } \\
\text { Autonomy }\end{array}$ & $\begin{array}{l}\text { The ability of a system to take decision with } \\
\text { the least amount of human input. }\end{array}$ & - Software & $\begin{array}{l}\text { (euRobotics } \\
\text { aisbl, 2015; } \\
\text { Moulianitis } \\
\text { et al., 2018) }\end{array}$ \\
\hline $\begin{array}{l}\text { Manipulation } \\
\text { Ability }\end{array}$ & $\begin{array}{l}\text { The ability of a system to handle material and } \\
\text { tools. }\end{array}$ & $\begin{array}{l}\text { - } \quad \text { Mechanical } \\
\text { - Control }\end{array}$ & $\begin{array}{l}\text { (euRobotics } \\
\text { aisbl, 2015; } \\
\text { Moulianitis } \\
\text { et al., 2018) }\end{array}$ \\
\hline Safety & $\begin{array}{l}\text { The ability of a system to operate by avoiding } \\
\text { hazards to the physical environment. }\end{array}$ & - All & $\begin{array}{l}\text { (Banerjee } \\
\text { et al., 2012) }\end{array}$ \\
\hline Security & $\begin{array}{l}\text { The ability of a system to ensure that its data } \\
\text { and its operational capabilities can only be } \\
\text { accessed when authorized. }\end{array}$ & $\begin{array}{l}\text { - } \quad \text { Electronics } \\
\text { - Software }\end{array}$ & $\begin{array}{l}\text { (Banerjee } \\
\text { et al., 2012) }\end{array}$ \\
\hline
\end{tabular}

The mechatronic properties outlined in Table 1 are critical in the usability of the devices. Indeed, even if a single of those properties does not meet the system's requirements, then it may render the mechatronic device useless. Consequently, if mechatronic devices are to be designed in a circular manner, it would be required to account for these properties. However, the main challenge is that these properties are highly linked to the electronics of the system, and thus highly prone to become obsolete. Furthermore, one other aspect to consider is that circularity might differ in meaning for the various engineering domains. Therefore, there might also be challenges related to the understanding of the circular design requirements. 


\section{Product Design in a Circular Economy}

As previously mentioned, a number of internal and external stakeholders contribute for the development of circular solutions. The designers/engineers for their parts could be seen as enablers: they should ensure that the product is, for instance, reusable, recoverable, and recyclable, and thus enabling a product to circulate. However, it is reported in different research work that one of the barriers of the $\mathrm{CE}$ is the technical knowledge. For instance, de Jesus and Mendonça (2018) reports that the availability of a technical solution (referred to as technical bottlenecks) is perceived as the biggest barrier for the successful implementation of a CE. At the same time, the technical aspect only accounts for the smallest driver. Moreover, Sumteret al. (2017) states that designers lack the know-how of assessing the circularity of a concept. For the CE to be successful, it should thus be necessary to have a paradigm shift in the development process of products in general and mechatronics in particular, and get product designers and engineers to drive the development of circular products. It would then require designing into the products multiple characteristics that would allow the product circulation in the value chain.

Consequently, the design for circularity entails to many challenges. It is mentioned that to keep a value in a product, designers would be required to prevent their obsolescence, and if not possible ensure that their constituent could be reused or recycled efficiently (den Hollander et al., 2017). This section presents the various methods that have been identified to design more circular products and elaborates on obsolescence, especially on obsolescence that could be relevant to mechatronics.

\subsection{Design methods and strategies for circular products: An Overview}

The design of circular products has been the subject of multiple research works. It is one of the main focus themes of the $\mathrm{CE}$, as better designing products would allow them to be circulated. The different definitions of the CE distinguishes between two types of loops: bio-based and technical (Sauvé et al., 2016). Bio-based loop are mostly focussed on trying to bring back the materials to the environment as nutrient. The technical loops aim at keeping products in use and reusing/remanufacturing/recycling the components of the system if not possible. The following overview will mainly focus on literature related to the technical cycles as it is the most relevant to mechatronic systems. The different research works will be presented in a chronological order.

First, Van den Berg and Bakker (2015) suggests a design framework where the product design should focus on two key characteristics: being future proof, and easy to disassemble. The ease of disassembly would in turn enable the circularity of the product by easing product maintenance, the remake of the product constituents (which encompasses refurbishing, remanufacturing and reconditioning), and finally recycling (Van den Berg and Bakker, 2015). There are also other aspects that need to be considered, such as for recycling where it not only relies on the ease of product disassembly, but also on the recyclability of the materials. In their design framework, Van den Berg and Bakker (2015) also mentions that the term reuse is to be avoided as it could interpreted differently, such as the reuse of product, reuse of parts or reuse of materials.

The work carried out by Bocken et al. (2016) outlines design strategies that would allow for circularities and are classified in 2 categories: Slowing resource loops and closing the loop. Since the goal of circular product design is to keep a product value as long as viable, the loop slowing strategy mainly focus on design methods that either result in extending the use life, such as by easing maintenance. Another strategy would be of having long-life product as by ensuring reliability and durability.

De los Rios and Charnley (2017) and Moreno et al. (2016) develop a detailed taxonomy of the product design methods that would allow for circular products. Moreno et al. (2016) identifies 5 design strategies in their conceptual framework that would allow for circularity: design for circular supplies, design for 
resource conservation, design for long-life products, design for multiple cycles and design for system changes. The work by Moreno et al. (2016) finally present a framework that maps the circular business strategies to product design strategies.

Den Hollander et al. (2017) approach the circular product design either designing for product integrity or for recycling. Den Hollander et al. (2017) defines design for product integrity as the focus on resisting, postponing or reversing product obsolescence. These objectives can be achieved through designing for long-use, extend-use or for (product) recovery. If not possible or viable to postpone obsolescence, Den Hollander et al. (2017) suggests that products should be designed to ensure efficient constituent recycling.

Based on Den Hollander et al. (2017), Kane et al.(2018) investigate the design of circular product in the medical field. They first outline that although multiple design strategies have been identified for circular product, research lack in the application of circular design for the various fields. For instance, a particularity of medical devices is their need to be sterilized/disinfected. Therefore, medical devices to be circular need to be able to recover from what Kane et al. (2018) refer to as hygienic obsolescence, which is the state where a product cannot be used for health reasons. They thus propose a framework to design medical devices based on the trade-off between the value of the product and its hygienic criticality.

Finally, Mestre and Cooper (2017) propose a life-cycle based framework which relies on either designing for a technical or biological cycle. The technical cycle strategy can be sub-divided into design for slowing the loop or closing the loop, whilst the biological cycle focus on bio-inspired or bio-based strategies. The framework proposed by Mestre and Cooper (2017) differs from other works as they consider the whole lifecycle as being a design strategy, with design methods/product characteristics overlapping in each life-cycle strategies.

Overall, the different design frameworks that have been developed mostly aims at the same goal, keeping the value of a product as long as possible, and economically viable. This is why they are often associated with business strategies (Bocken et al., 2016; Moreno et al., 2016) since the "value" of a product would be highly dependent on it. Furthermore, they are highly general, and thus might not all be well adapted for highly multi-domain products. It is thus necessary to investigate the implications of these frameworks in terms of required product properties.

\subsection{Key Circular Product Properties}

Each of the aforementioned research works proposed design methods or framework that would allow product circularity. It can be seen in their description that they overlap, which is detailed in Figure 2 . The similarity between the strategies is that they often refer to either slowing-loops or closing loops. Blomsma et al. (2018) instead distinguishes between 4 circular strategies (loop-closing, loop extending, preventive, longevity and intensification) which could have different enabling methods. Regardless the way that the circularity strategies are defined, they all break down to a set of product "capabilities" (den Hollander et al., 2017; Potting et al., n.d.; Van den Berg and Bakker, 2015), which are provided in Table 2. Of course, it is necessary to point out that none of these capabilities should be seen as better than another, but they should be designed into the products depending on the customer requirements or business model. 
Table 2: Product Capabilities for Circularity

\begin{tabular}{|c|c|}
\hline Capability & Definition \\
\hline Durability/Reliability & The system can keep performing its intended purpose for a long period \\
\hline Upgradeability & $\begin{array}{l}\text { The system can be brought to a higher level of functionality than initially } \\
\text { intended }\end{array}$ \\
\hline Repairability/Maintainability & The system functionalities can be kept at the intended initial level \\
\hline Reusability & $\begin{array}{l}\text { The system can be reused by other stakeholders with the same level of } \\
\text { functionalities as initially intended }\end{array}$ \\
\hline Refurbishability & The system (or its constituents) functionalities can be restored \\
\hline Remanufacturability & $\begin{array}{l}\text { The system (or its constituents) can be brought back to the same level of } \\
\text { functionality/quality as initially intended, or to higher standards, so it } \\
\text { can be used in a new system }\end{array}$ \\
\hline Repurposability & $\begin{array}{l}\text { The system (or its constituents) can be used to other purpose (or in other } \\
\text { products) than what it was originally intended for }\end{array}$ \\
\hline Recyclability & The system constituent can be recycled \\
\hline Recoverability & The system constituent can be incinerated to recover some energy \\
\hline
\end{tabular}

Moreover, these circular capabilities would have an effect on the use phase of the product. Indeed, they would allow to a certain extent to keep the products to become obsolete. Obsolescence is defined as being the loss of perceived value of a product (den Hollander et al., 2017). The value of a product can be different meaning depending on the stakeholder. For instance, the value of a product from the user's perspective would not be the same as the one from the manufacturer. Hence, there are multiple types of obsolescence and we outline here the ones that are deemed the most critical to mechatronics. These obsolescence types are functional, technological, logistical, economic, regulatory, and social. They are detailed in Table 3. 
Table 3: Description of Obsolescence Types

\begin{tabular}{ll}
\hline Type & Description \\
\hline Functional & Functional obsolescence occurs when a device cannot achieve its intended requirements, \\
& which can happen when parts of the product is broken or when product's requirement \\
are changed. (Bartels, 2012). This can occurs in hardware/software development where & for instance a software change could result in the hardware not being able to support the \\
& new software, or a software that is not supported by a newer hardware (Rajagopal et al., \\
& 2014; Sandborn, 2007). \\
\hline Technological & $\begin{array}{l}\text { Technological obsolescence occurs when new, better performing, products comes out } \\
\text { and that suppliers stop manufacturing or supporting the older products (Bartels, 2012; }\end{array}$ \\
& Clavareau and Labeau, 2009). \\
\hline Logistical & $\begin{array}{l}\text { Logistical obsolescence occurs when the means of producing/acquiring a product cease } \\
\text { to be available. This can occur for instance when the equipment used to manufacture a } \\
\text { product are no longer available (Bartels, 2012) or when the media used to distribute a } \\
\text { software is no longer supported (Sandborn, 2007). }\end{array}$ \\
\hline Economic & $\begin{array}{l}\text { Economic obsolescence occurs when it is no more economically viable to continue using } \\
\text { the product. This could occur for instance in the case of a broken product, such as a } \\
\text { toaster, which would be costlier to repair than to buy a new one. }\end{array}$ \\
\hline Regulatory & $\begin{array}{l}\text { Regulatory obsolescence occurs when a product or part of product is outlawed. This } \\
\text { does not imply that functionalities or technologies of the product are obsolete. An } \\
\text { example of recent regulatory obsolescence would be the ban of diesel cars by the } \\
\text { German municipalities (Connolly, 2018). Sometimes, the whole product is not } \\
\text { necessarily banned as in the case of diesel cars, but only some parts such as the engine } \\
\text { in this case. }\end{array}$ \\
\hline Social/ & $\begin{array}{l}\text { Social or Aesthetic obsolescence occurs when the product is no more used or desired } \\
\text { because of changes in trends. }\end{array}$ \\
\hline Aesthetic &
\end{tabular}

It is clear that the obsolescence type could be mitigated with the circular capabilities depending on the product requirements. For instance, functional obsolescence could be delayed if the product is durable and upgradeable. Other products may need other circular capabilities to keep being used, and it is thus case dependent.

Nevertheless, it is still possible to observe a trend in the circular product capabilities of Table 2 and how they would be implemented. Indeed, it is possible to identify two main key properties that should allow to integrate circular design principle: Robustness and Modularity.

First, a robust design is defined as the reduced sensitivity of a device to uncertainties (Sibalija and Majstorovic, 2012). The uncertainties in the device can be related to manufacturing errors, wear, tear, and deterioration of the components, or changes in the operating environment. Therefore, a system that is robustly designed implies that even though uncertainties are presents, it will still operate in a satisfying manner. Hence robustness would need to be designed in circular products in order for them to be longlasting. However, there would always be a trade-off between optimal functionality and robustness, as they would often be contradicting design objectives. This is also true for mechatronics which add the difficulty of ensuring robustness through different engineering domains.

Moreover, a system can also be designed to be modular in terms of functionality or in terms of structure. This modularity allows much of the circular design methods to be carried out. Indeed, it is reported by 
Sonego et al. (2018) and Yan and Feng (2014) that modularity could enable more efficient recycling by easing disassembly, or by enabling upgrade by changing sub-systems. Modularity often comes up in the circular product design research work, such as by Kane et al. (2018) where one of the example used is a surgical shaver for which heads are reprocessed by the manufacturer to comply with health regulations, but the rest of the body can be reused, thus reducing the impact of the product compared to single use shavers.

It is to note that some of the circular capabilities of Table 2 are the result of the combination from those two properties. It is also obvious that each circular product capability would require more than only the key properties, but they should not be achievable if they are not present. A representation of the properties in relation to the circular strategies is also shown in Figure 2.

Furthermore, both modular design and robust design are important aspects of mechatronic design and still are subject to intensive research by the community. Indeed, multiple work proposes methodologies for robustly designing mechatronic systems (Alyaqout et al., 2011; Chouinard et al., 2019b; Coulombe et al., 2017; Villarreal-Cervantes et al., 2013). Moreover, modular mechatronic design has also been highly investigated such as done for instance by Schuh et al. (2016) or by van Beek,Erden and Tomiyama (2010). Consequently, it can be hypothesized that mechatronic devices are well suited to be integrated to the circular economy as they should already be designed considering the identified key properties, namely modularity and robustness. Hence, it is necessary to investigate if mechatronic engineers do need to worry about it after all, or that it would only require minor changes.

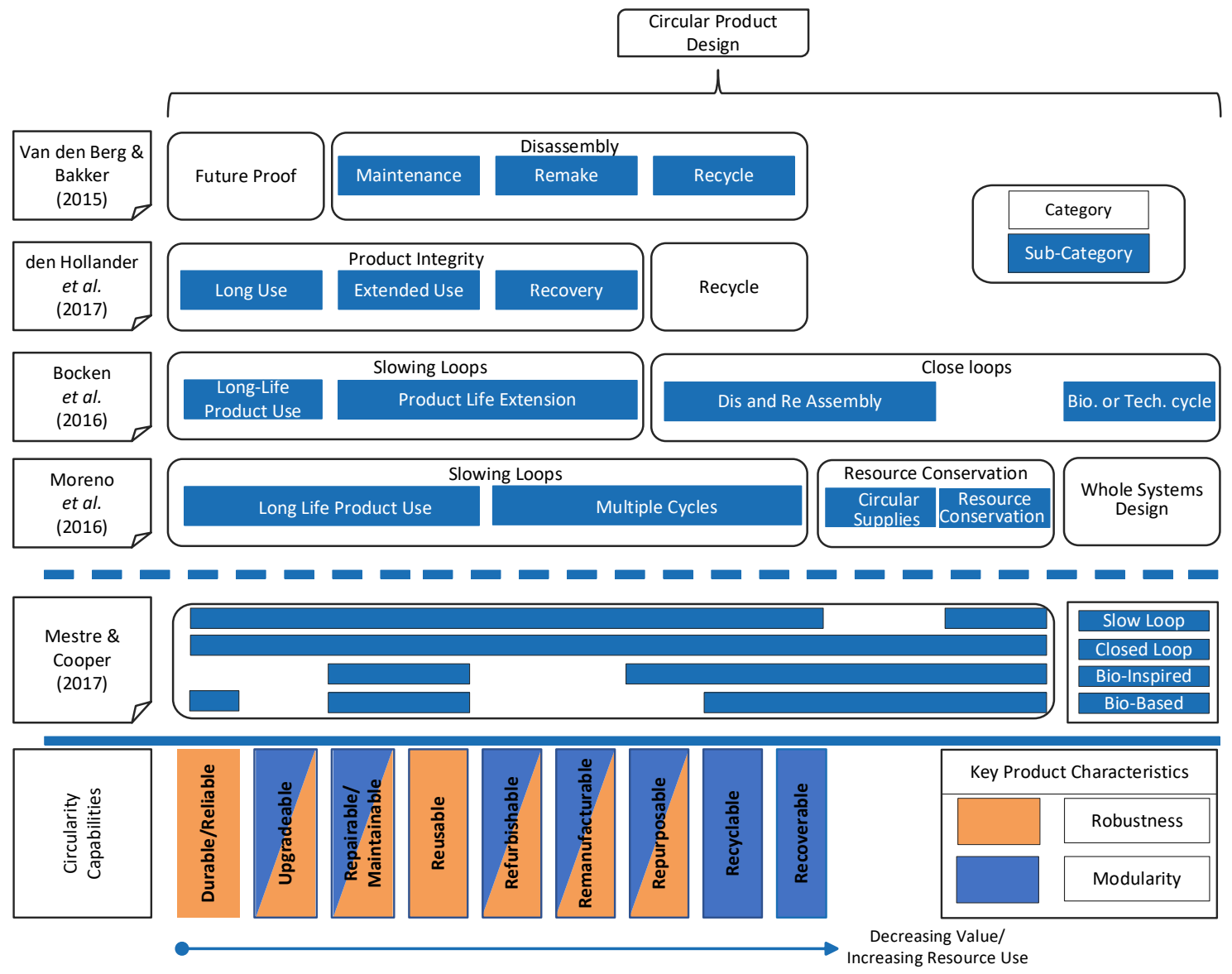

Figure 2: Mapping of the Circular Design Strategies with the Product Properties 


\section{Circularity in Mechatronics}

An online survey ${ }^{1}$ was conducted from 26/06 to 01/09 2018 to better understand which of the circularity characteristics were currently designed into the various mechatronic products. Moreover, the survey focussed on finding why and how circularity aspects were designed, and to determine which the challenges were with respect to dealing with obsolescence.

Throughout this section, we first present the results of the survey. Then we elaborate on the implementation of circularity in the mechatronics domain, and what can be improved in the design process.

\subsection{Findings from the survey}

\subsubsection{Respondents' Profile}

In total, there were 28 respondents to the survey, for which their background is provided in Figure 3. Most of them (63\%) were working in the Automation/Manufacturing and Robotics fields. Moreover, most of the respondents had some level of knowledge about the CE. Finally, although the number of respondents is limited, there was a substantial amount of them having a lot of experience in the domain. Indeed, a third of the respondents were working in the field for over ten years which would categorise them as mechatronics design experts. However, lacking sufficient number of respondents for statistical purpose, the survey analysis will be carried out in a descriptive manner. Nevertheless, it is worth noting that the most common technique used for decision support in industries is expert knowledge and judgment and there is no agreement about the sample size and no standards by which a sample size selection could be evaluated to select the number of expert participants required (Lai et al., 2006). To assess the generalisation of the results, several woks in product development base their conclusions on a number of experts ranging from 4 to 7 (Achiche et al., 2012; Strasser et al., 2005). Therefore, we can argue for the value of the findings of the survey but whenever percentages are used, it is more for the reader's convenience than actual statistical values.

Based on the background information collected from the respondents, two key points were outlined. First, the mechatronic products the respondents were working with all required to be functioning for over $10^{3}$ hours, while the majority from $10^{4}-10^{5}$ hours, and more ${ }^{2}$. Then, when asked to rate the complexity of the mechatronic products they were working with on a scale from 1(very low) to 10 (very high), $70 \%$ of respondent rated it at 7 and higher, with 8 being the median value. These points define the challenges arising from mechatronics development and are influencing the way the systems are designed. Indeed, mechatronic devices are highly complex and are usually required to perform continuously to reduce their downtimes due to failures.

\footnotetext{
${ }^{1}$ This survey is kept available for reference at: https://goo.gl/forms/VJvDbYZRmP9ej3tY2

${ }^{2}$ The initial expected lifetime is expressed in hours as compared to years since multiple mechatronic devices are required to operate the vast majority of the day. $10^{4}$ hours represents the device functioning continuously for over a year.
} 


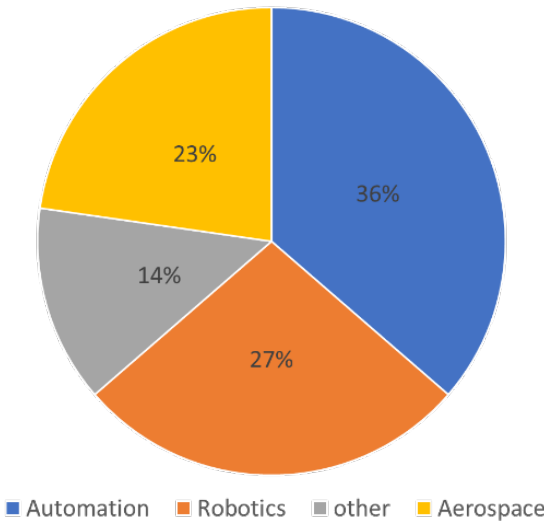

(a)

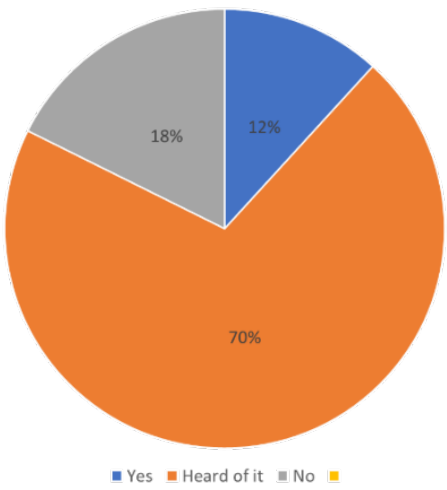

(c)

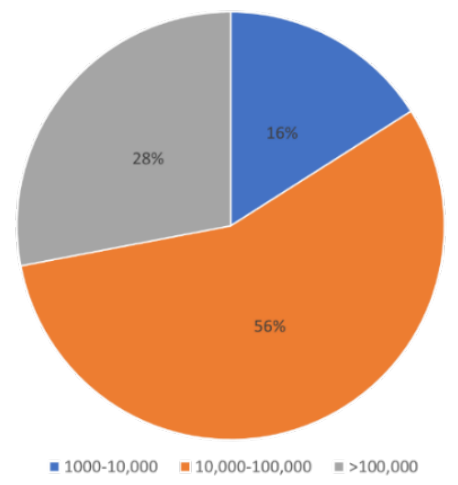

(d)

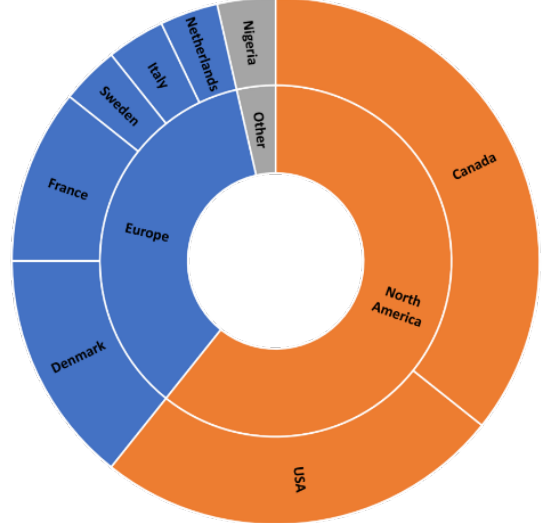

(b)

Figure 3: Distribution of respondent based on (a) Industry sector, (b) Geographical Area, (c) Knowledge about CE (d) product's expected lifespan in hours, (e) Years of experience

\subsubsection{Customer Requirements Influence}

It was outlined in Section 4 that there were various product properties that would allow to adopt circular design strategies. In terms of mechatronic products, the strategy that could be said to be in place is the "long-looping" of products. Indeed, the respondents mentioned that they all included the circular product properties that would fit under this long-life strategy. Figure 4 shows which circular capabilities were often included.

Obviously, customer demands are the highest priority in the design of any product. Consequently, when asked about the reasons to include the various CE properties, most of the ones that were included were based on customer requirements and expectations, as shown in Figure 3. Mechatronic devices are required to be long-lasting, but the end of life (EOL) is not usually considered in the design of these systems. The only respondents that considered EOL (mostly recycling) were ones coming from companies that did implement eco-design/CE principles, as shown in Figure 5. These observations are in line with Atlason et al. (2017) that mentions it is not interesting for companies to design recyclable products if the customers rather have long-lasting and repairable ones.

The survey respondents also mentioned that there were "too many factors [for circularity], [and that the] customer demands come first". Moreover, the $\mathrm{CE}$ was seen as "positive, but priority [is] given to customer demands". Finally, respondent mentioned that the "new concepts in engineering have to be accepted by customers". 
Therefore, currently from a mechatronic engineer's point of view, the changes to the design process will come from the customer, otherwise there is no incentive for changing the design process. Indeed, the respondents mentioned that doing so would necessarily require "more complex and deep design" or that it would require to "spend more time on the design phase". Respondent mentioned that this would be linked to the product requiring to "fulfill other requirements than the original needs". From the respondents' point of view, going towards more circular product will only be possible if "design directives [are] changed and [that] system [are] developed to make circular products economically advantageous" or that it "will be adopted if it has economic advantages". Changes should thus be made to "customer selection, marketing/sales processes" before circularity is adopted in the design process.

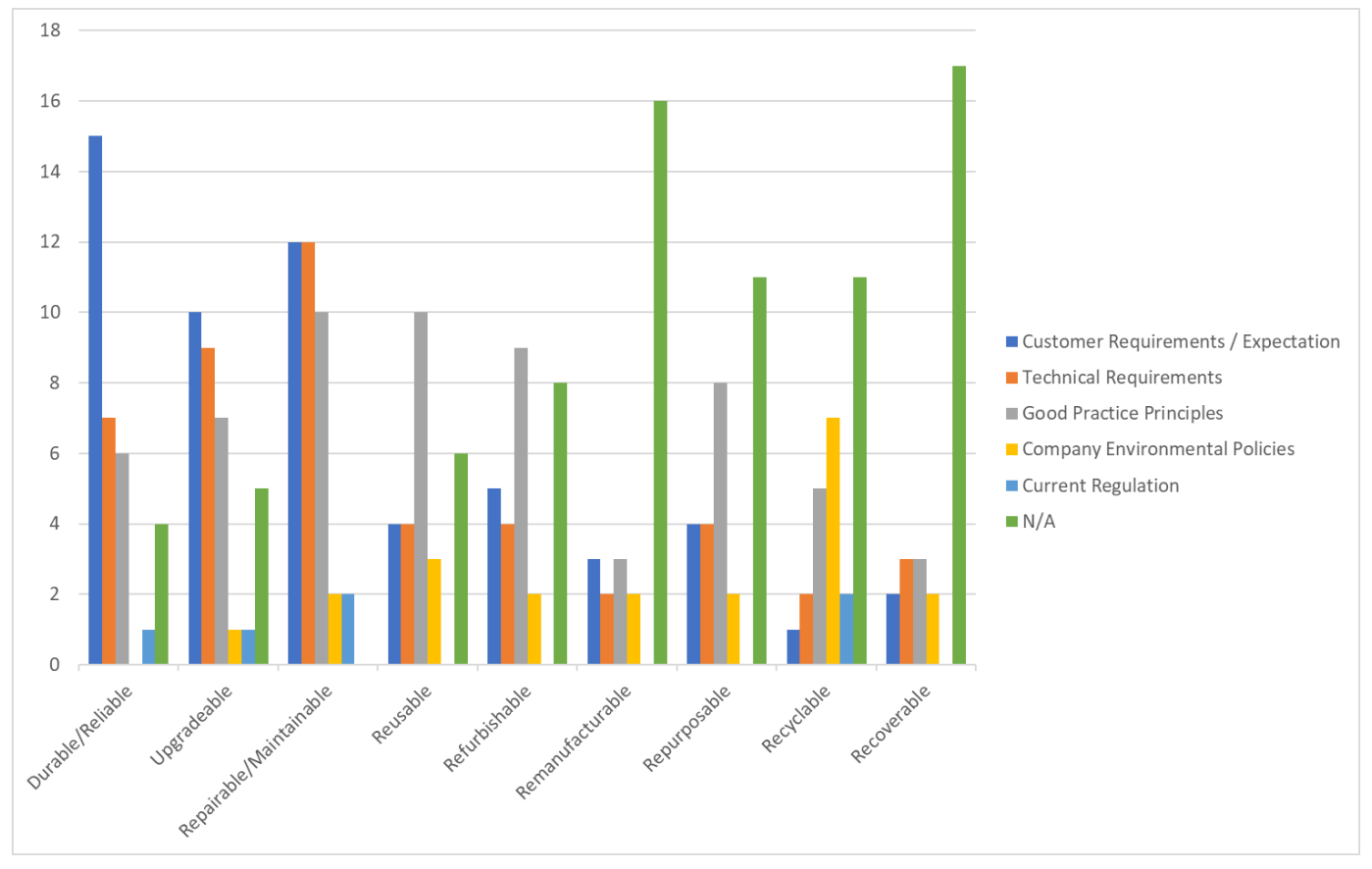

Figure 4: Reasons to design circular capabilities 


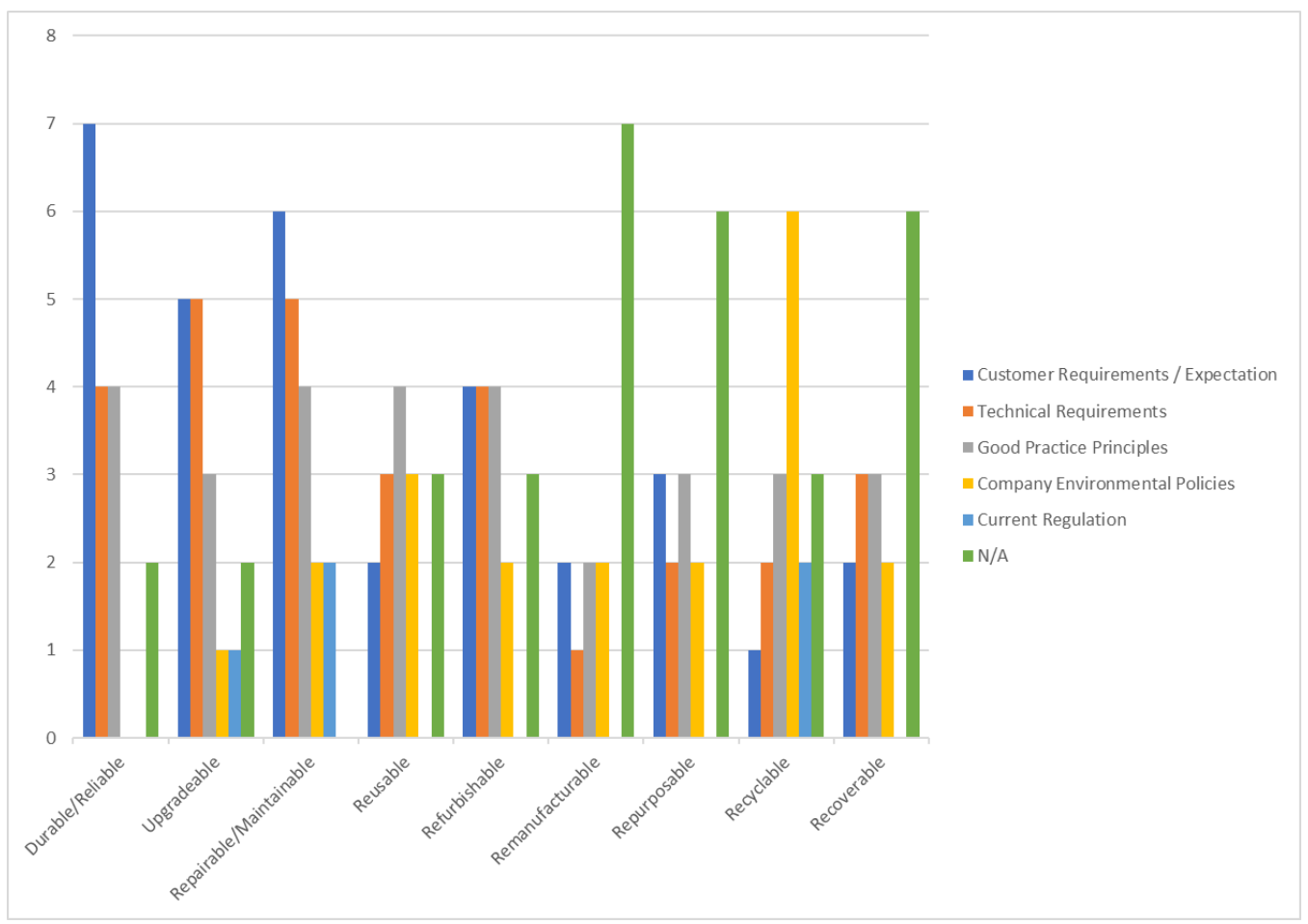

Figure 5: Reasons to design circular capabilities when companies considers eco-design/CE

\subsubsection{Functionality and Technology the biggest challenges in designing circular mechatronic products}

It is stated in the previous section that the circularity of mechatronic devices would mainly be based on the customer requirements, and it was pointed out that the closest to a "circular strategy" that could say to be adopted in the design process is for long-loops. Even considering this strategy is highly challenging for mechatronic engineers. When looking at product obsolescence, the most likely aspects to become obsolete are functional and technological, which is shown in Figure 6.

Reasons provided to the difficulty of keeping mechatronic products in use are for instance "the imperative need for up-to-date performances (electronics)". Moreover, also considering electronics, it is mentioned that one reason to discontinue mechatronic products is that "most of the time is that some supplier will just stop producing certain chips".

It is also mentioned by respondent that "requirements of the product is likely to change over time (can be imposed by regulations). Therefore, we should design systems that can constantly be adapted/reconfigured, and they must be usable for a long period of time. [..] the components must [also] be reliable because they are used a lot". These are often contradicting objectives as mentioned in the previous section since adaptability/configurability would be related to modularity, and that durability to robustness.

Finally, one challenge that needs to be considered is the short development time needed for these types of products. Indeed, it is mentioned that it would be "difficult for a fast-paced environment, [it] requires additional reviews and oversight", or that "in general harder to make mechatronics system circular since the pace of development is extremely high". This again links back to the need for customer to require circularity of the mechatronic products and thus accept longer development process. 


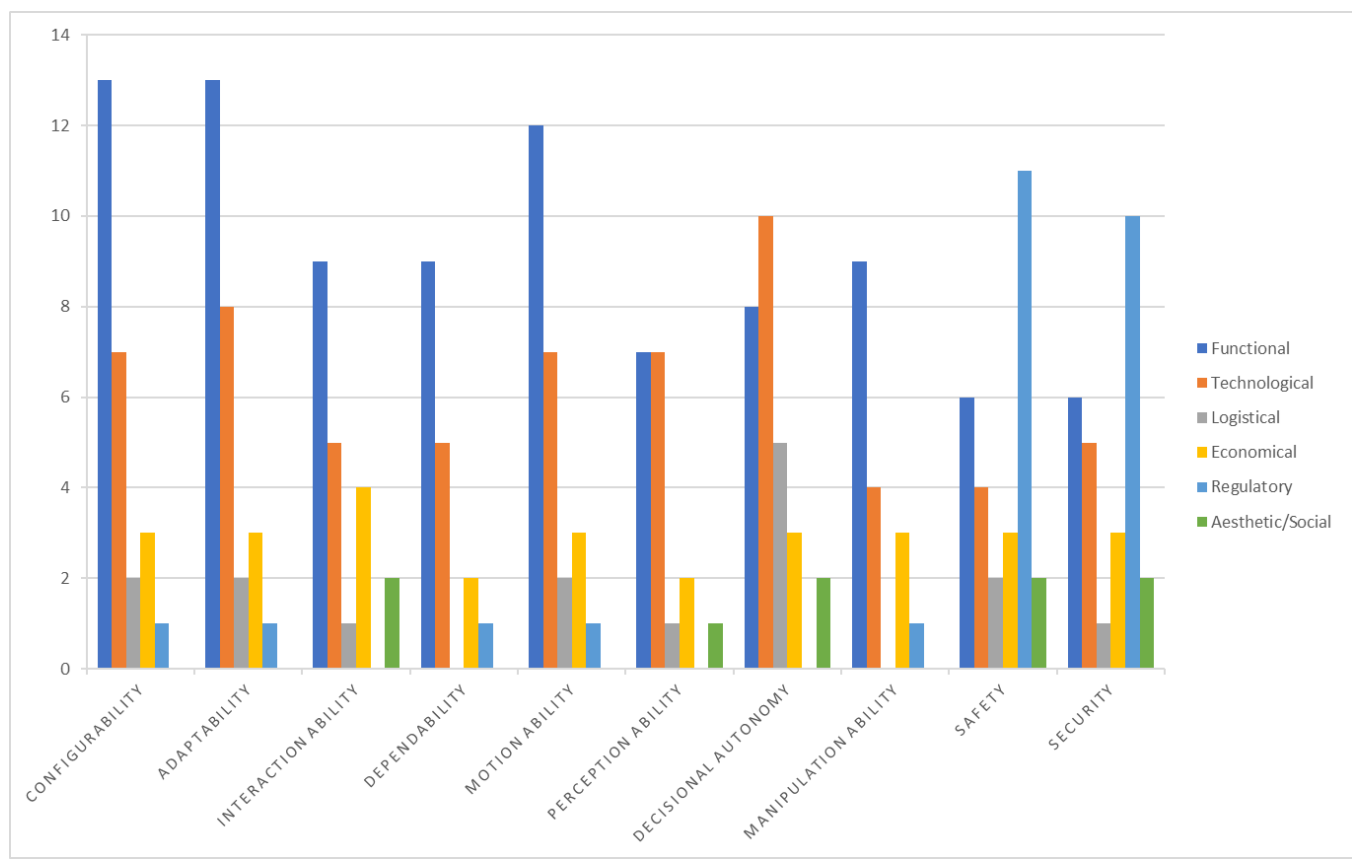

Figure 6: Most Likely Causes for Mechatronic Properties Obsolescence

\subsubsection{Constraints to implementing circularity}

One of the other major concerns in mechatronic design would be related to regulatory obsolescence. Figure 6 displays that for the safety and security aspects, this would be the most prominent cause. It is to note that $19 / 26$ respondent mentioned that these two aspects were required in their mechatronic devices. Moreover, respondent mentioned that difficulties considering the design of circular mechatronics would be related to the "Stability for Safety norms" and that for instance "there is some restrictions in aviation, as we must follow closely regulations, we sometimes have no choice but to use technologies and we have no real power to change/re-design it".

The various industries that uses mechatronic devices within their products are often highly regulated. Indeed, when looking at the development process of robotic systems, automobiles or manufacturing plants, they often have to comply with international standards related to, for instance, functional safety (IEC 61508, ISO 26262, ISO 13849, IEC 62061). The development of devices under those standards is highly rigorous and time consuming. Therefore, implementing properties in the mechatronic products that would not be directly required might not be feasible, as the development process would be too costly, and the nonrequired features might be a violation of the applicable standard. Therefore, it is perceived as being "of low relevance [...] as requirements of safety, reliability and cost overrule risks inherent in moving to circular models".

\subsection{Do mechatronic engineers need to worry about the Circular Economy?}

Strictly speaking, companies involved in mechatronics could easily state that their products are circular as they could be said to follow an "Extended-Loop" or "Long-Loop" design strategy. However, doing so would not be the required "paradigm shift" that the CE is intended to create.

In general, most of the respondents were open to the idea of a CE. They, for instance, mentioned that "it's smart to keep in mind", that it is "useful but unapplied honestly" and it is a "great idea". However, the respondent usually had restraints in the applicability of the CE as it was mentioned that it is "Ambitious, Useful, but hard to implement in practice" and they felt that "ethical, not economical design principles are 
the driving force of the circular economy". This response would be linked to another respondent mentioning that it is "very important to save our future resources (the Earth) and life environment - but [circular economy is] completely out of scope in the world of mechatronic design".

It can be seen that mechatronic engineers do not perceive added value of circularity. It can be hypothesised that the aforementioned statements mostly relate to the fact that companies often do not keep ownership of their product. Hence, unless the customer intends to circulate the mechatronic products themselves, they would have no interest in EOL properties. However, if other business strategies are adopted, such as from a product/service systems (PSS) perspective, then designing-in the EOL properties would not be a customer requirement anymore, but a company need. Therefore, the mechatronic engineer will have an incentive to spend more time during the design process to ensure that the mechatronic product have the required properties.

Therefore, in terms of mechatronic design, considering circularity aspect would in part require multiple changes to the design process. First it is clear and acknowledged by the engineers that there is a need for a "better handling of the end of the normal life cycle". Moreover, including the later stage of the product life cycle would "require changes in the design of mechanical components, re-designing parts to make sure they can be refurbished". Finally, another respondent mentions that it would be required to adopt "Smart programming practices to enable reuse of software and hardware systems".

\subsection{Survey Limitations}

The survey that was carried out do have some limitations concerning the scope. Obviously the major one being the number of respondents to analyse statistically the results. One other limitation in the analysis is the type of products that the mechatronic engineers were working with. Most of them were working in the automation and robotics, aviation or automotive sectors. Only one responded reported to be working with consumer mechatronic products. This greatly affect the properties that are designed in the product since the requirement would greatly vary. Indeed, the expected lifetime of the surveyed products are much higher than what would be expected from consumer products and thus the long-life strategy might not be present in the later. Consequently, it would be necessary to investigate the difference in the designed properties for consumer mechatronic devices.

\section{Discussion:}

\subsection{Current State of Mechatronic Circular Design}

The literature review and survey results provided initial insights on the circular economy implementation in mechatronics. Regarding RQ1, it was determined that a product could display 9 properties, or as they were called previously in section 4.2, circular capabilities. These circular capabilities were in turn relying on two main properties: modularity and robustness. Based on the survey, it was determined that the circular capabilities often displayed by mechatronic devices were the ones related to the robustness key property. Indeed, the engineers were often designing-in long-lasting products based on customer expectations and requirements. The least applicable capabilities were found to be the ones relying more on the modularity aspect, which were capabilities related to the dismantling of the system such as recycling, or remanufacturing.

This might be explained by the fact that modularity is not necessarily understood in the same by the mechatronic engineers. Indeed, the modularity of the functions may not result in modularity of the components. This implies that if the system has different submodules to achieve its intended functionality, the submodules themselves could well be highly integrated and thus not necessarily disassembled. There is thus more work that needs to be carried in that sense as to better determine how the modularity that is 
designed in the mechatronic system could be used to facilitate the implementation of circular strategies such as remanufacturing, refurbishment and recycling. Indeed, it was determined by Reale et al. (2015) for the life-cycle assessment of a mechatronic system that manually disassembling the product would have a lower environmental impact than mechanical separation. Hence, better linking the mechatronic modularity to the required modularity for efficient recycling should greatly enhance the environmental performance of the devices.

\subsection{Challenge of Circularity in Mechatronic Design}

One of the elements of research stated in RQ2 was to determine which were the challenges associated with the implementation of circularity in mechatronics. It was reported that the main challenges observed by the engineers were related to the obsolescence of the system's functionality and the underlying technology allowing to achieve this functionality. It is clear that obsolescence should be a major point of concern when developing methods and tools for the mechatronic design process. New methods should be developed to help mechatronic engineers to better make decisions as to which design or concept would allow greater circular capabilities by avoiding the systems and/or specific components to become obsolete.

Furthermore, another challenge that mechatronic engineer faces is related to the compliance with regulation, which would be a major obsolescence factor. As previously stated, the respondents mentioned that safety requirements would have predominance over the implementation of optional circular capabilities. On top of safety requirements, each application field has its own regulation which need to be accounted for. Finally, it is also worth noting that mechatronic devices still need to comply to environmental regulations such as the WEEE and ROHS directives. It is clear that there are many factors to consider when developing mechatronic systems and thus it is necessary to ease the integration of the various and often conflicting requirements. Consequently, new design methods and tools should be developed to address the challenge of integrating safety/regulation compliance with circularity.

There is another challenge that is not necessarily clearly stated by the survey, but which can be understood from the written responses: there is still a lot of work to be done in order to show the added value of carrying out circular design. Indeed, as it was outlined in section 5.1.2, the mechatronic engineers will not shift to circular activities unless required to do so. Consequently, there is a need to develop methods that will facilitate the integration of circular principles. Those circular principles would not necessarily be related to implementing what we termed as circular capabilities, but also other sustainability principles such as to reduce the environmental impact of the device by analysing the life-cycle of the mechatronic product. This could be achieved by facilitating the use of LCA tools, or by increasing the use of eco-design principles related to, for example, minimization of energy consumption.

Consequently, the challenges that would need to be addressed are summarized as such:

1. Avoidance of functional and technological obsolescence;

2. Integration of circular properties while complying to standards and regulations;

3. Showing the added value of designing circular products.

\subsection{Improving the Design Process for Better Circularity}

The last element of research that was considered in this work was to determine what needed to be improved in order to have more circular mechatronic products (RQ3). As previously mentioned, there would need to develop methods and tools that would facilitate the integration of LCA or eco-design principles. In terms of actions that could be undertaken by mechatronic companies to improve the circular potential of their product, we identify two elements that should be achievable in the short run: 
1. Easing Remanufacturing,

2. Using Adaptable, Reconfigurable Electronics.

\subsubsection{Easing remanufacturing}

One of the challenges for mechatronic engineers is including characteristics concerning the end-of-life so that it is beneficial for their company. A way to do so is to ease the remanufacturing process. Indeed, remanufacturing is a crucial process to reduce waste while allowing to provide good as new part for a lesser cost. The Ellen MacArthur Foundation provides case studies that shows how OEM successfully provides a remanufacturing service (Ellen MacArthur Foundation, 2019a). Although handling the remanufacturing process can be of interest for larger companies, it might be less feasible for Small-Medium Enterprise to invest in the required infrastructures.

However, it is not necessarily the OEM that would need to carry out remanufacturing. Indeed, there is a large industry revolving around remanufacturing of mechatronic devices. Nevertheless, there are still a lot of challenges associated to it such as the reverse logistic supply chain (Sundin and Dunbäck, 2013), or the reverse engineering of the mechatronic devices (Freiberger et al., 2011). Therefore, instead of investing in remanufacturing plants, OEMs could create partnership with well established remanufacturing company to ease the logistical and reverse engineering aspect of the process, which is starting to be done (Ellen MacArthur Foundation, 2019).

Therefore, from the OEM perspective there could be two different ways that remanufacturing could be implemented to increase value. On top of that, the remanufacturing aspect would be even more attractive in the case of PSS business cases.

\subsubsection{Using Adaptable, Reconfigurable Electronics or Distributed Systems?}

It is well understood that the electronic aspect of mechatronic devices is crucial for their proper functioning. It was previously outlined that this is often a cause of mechatronic product obsolescence and is also a major concern in terms of EOL management. For instance, it is mentioned by Reuter et al. (2018) that although electronic products such as the Fairphones are designed with sustainability in mind, there is only a limited amount of material that can be effectively recycled. There is thus a need to instead keep components and subsystems in use as this would allow to retain the most value. However, electronics become obsolete quite rapidly and there is thus a need to be able to adapt them. One potential solution is suggested by Bossuet (2014) which mentions that reprogrammable electronics such as Field Programable Gate Array (FPGA) could be used. However, this would necessarily involve design changes and might complexify the development process as FPGA might not be commonly used in certain companies. Another potential solution is the use of distributed architecture for additional functionalities. Indeed, new trends in the development of artificial intelligence and the interest in increasingly more autonomous machines could lead to premature obsolescence of existing mechatronic devices. Instead of this, it could be possible to move towards cyber-physical systems (CPS) (Banerjee et al., 2012; Hehenberger et al., 2016) which would then allow to add functionalities without changing the embedded electronics.

\section{Conclusion}

This paper investigated the current state of design related to the circular economy in mechatronics. First, the paper, based on a literature overview, outlined two key product properties that should allow for circularity, especially in mechatronics. These two properties were the modularity and robustness of a product. It was then assumed that since those properties were often considered when designing mechatronic devices, these systems would thus be well suited to display circularity properties. To verify this, a survey was distributed to practicing mechatronic engineers. The survey showed that product properties linked to long-loop or loop-extending strategies were often designed into mechatronic devices, but the end-of-life 
was rarely considered. Moreover, it was found that although most respondent thought that circular economy at his core was positive, it may not be of relevance in mechatronics. This was mainly due to mechatronic engineers not seeing the value of circular products since it was not a customer requirement.Consequently, some suggestions were made to improve the end of life characteristic of mechatronic system by easing remanufacturing or by postponing obsolescence of the system's electronics.

However, it is clear, as it was pointed out in the paper, that the said paradigm shift the CE aims to create may be very challenging to implement in mechatronics. There is still reluctance from the engineers and from the companies to better manage the end of life of their devices. Indeed, unless customers require to have more recyclable or repurposable systems, there will be no incentives. There is then a need to shift to other business models that would make end of life properties more attractive, such as Product-Service Systems.

Finally, one thing that needs to be considered in future work is how to provide better support to mechatronic engineers for integrating CE. Indeed, mechatronic systems being of multi-domain nature, there is a lot of work to be done in determining how to include circularity in an integrated manner. There is thus a need to investigate the implication of all engineering domains in the circularity properties and not only the domains that are related to physical entities.

It is clear that this research being an exploratory study, there is still a lot of work to be done to support mechatronic engineers to design even more circular products. Nevertheless, this work still gives a good idea of the current state of design practices related to the circular economy. It can thus be used by other researchers as a steppingstone for the development of new methods and tools.

\section{Acknowledgements:}

This research was supported by the Natural Science and Engineering Research Council of Canada and by the Institut de l'Énergie Trottier/Hydro-Québec.

\section{References}

Achiche, S., Appio, F.P., McAloone, T.C., Di Minin, A., 2012. Fuzzy decision support for tools selection in the core front end activities of new product development. Res. Eng. Des. 24, 1-18. https://doi.org/10.1007/s00163-012-0130-4

Alyaqout, S.F., Papalambros, P.Y., Ulsoy, A.G., 2011. Combined Robust Design and Robust Control of an Electric DC Motor. IEEEASME Trans. Mechatron. 16, 574-582. https://doi.org/10.1109/TMECH.2010.2047652

Atlason, R.S., Giacalone, D., Parajuly, K., 2017. Product design in the circular economy: Users' perception of end-of-life scenarios for electrical and electronic appliances. J. Clean. Prod. 168, 1059-1069. https://doi.org/10.1016/j.jclepro.2017.09.082

Banerjee, A., Venkatasubramanian, K.K., Mukherjee, T., Gupta, S.K.S., 2012. Ensuring Safety, Security, and Sustainability of Mission-Critical Cyber-Physical Systems. Proc. IEEE 100, 283-299. https://doi.org/10.1109/JPROC.2011.2165689

Bartels, B., 2012. Strategies to the prediction, mitigation and management of product obsolescence, Wiley series in systems engineering and management. Wiley, Hoboken, N.J.

Blomsma, F., Brennan, G., 2017. The Emergence of Circular Economy: A New Framing Around Prolonging Resource Productivity: The Emergence of Circular Economy. J. Ind. Ecol. 21, 603614. https://doi.org/10.1111/jiec.12603

Blomsma, F., Kjaer, L., Pigosso, D., McAloone, T., Lloyd, S., 2018. Exploring Circular Strategy Combinations - towards Understanding the Role of PSS. Procedia CIRP 69, 752-757. https://doi.org/10.1016/j.procir.2017.11.129 
Bocken, N.M.P., de Pauw, I., Bakker, C., van der Grinten, B., 2016. Product design and business model strategies for a circular economy. J. Ind. Prod. Eng. 33, 308-320. https://doi.org/10.1080/21681015.2016.1172124

Bossuet, L., 2014. Sustainable electronics: On the trail of reconfigurable computing. Sustain. Comput. Inform. Syst. 4, 196-202. https://doi.org/10.1016/j.suscom.2014.07.001

Chouinard, U., Achiche, S., Baron, L., 2019a. Integrating Negative Dependencies Assessment During Mechatronics Conceptual Design using Fuzzy Logic and Quantitative Graph Theory. Mechatronics.

Chouinard, U., Achiche, S., Leblond-Ménard, C., Baron, L., 2017. Assessment of dependencies in mechatronics conceptual design of a quadcopter drone using linguistic fuzzy variables. Presented at the 21st International Conference on Engineering Design, Vancouver, Canada, pp. 031-040.

Chouinard, U., Achiche, S., Santos, I., Baron, L., 2019b. Robust Design Support using Fuzzy Simulation of Uncertain Dynamic System: A Self-Balancing Robot Case Study, in: DINAME 2019. Presented at the International Symposium on Dynamic Problems of Mechanics, Armação de Búzios - RJ Brazil.

CIRAIG (International Reference Center for the Life Cycle of Products Processes and Services), n.d. Circular economy: A critical literature review of concepts. Montreal, Quebec, Canada.

Clavareau, J., Labeau, P.-E., 2009. Maintenance and replacement policies under technological obsolescence. Reliab. Eng. Syst. Saf. 94, 370-381. https://doi.org/10.1016/j.ress.2008.03.033

Connolly, K., 2018. German court rules cities can ban diesel cars to tackle pollution. The Guardian.

Coulombe, C., Gamache, J.-F., Mohebbi, A., Chouinard, U., Achiche, S., 2017. Applying robust design methodology to a quadrotor drone. Presented at the 21st International Conference on Engineering Design, Vancouver, Canada, pp. 395-404.

de Jesus, A., Mendonça, S., 2018. Lost in Transition? Drivers and Barriers in the Eco-innovation Road to the Circular Economy. Ecol. Econ. 145, 75-89. https://doi.org/10.1016/j.ecolecon.2017.08.001

De los Rios, I.C., Charnley, F.J.S., 2017. Skills and capabilities for a sustainable and circular economy: The changing role of design. J. Clean. Prod. 160, 109-122. https://doi.org/10.1016/j.jclepro.2016.10.130

den Hollander, M.C., Bakker, C.A., Hultink, E.J., 2017. Product Design in a Circular Economy: Development of a Typology of Key Concepts and Terms: Key Concepts and Terms for Circular Product Design. J. Ind. Ecol. 21, 517-525. https://doi.org/10.1111/jiec.12610

Ellen Macarthur Foundation, 2019. Design and business model considerations for heavy machinery remanufacturing [WWW Document]. URL https://www.ellenmacarthurfoundation.org/casestudies/design-and-business-model-considerations-for-heavy-machinery-remanufacturing (accessed 1.13.19).

Ellen MacArthur Foundation, 2019. Remanufacturing in the automotive industry [WWW Document]. URL https://www.ellenmacarthurfoundation.org/case-studies/remanufacturing-in-the-automotiveindustry (accessed 1.13.19).

Ellen MacArthur Foundation, 2018. The Circular Economy Concept - Regenerative Economy [WWW Document]. URL https://www.ellenmacarthurfoundation.org/circular-economy/overview/concept (accessed 8.21.18).

euRobotics aisbl, 2015. Robotics 2020 multi-annual roadmap for robotics in Europe.

Freiberger, S., Albrecht, M., Käufl, J., 2011. Reverse Engineering Technologies for Remanufacturing of Automotive Systems Communicating via CAN Bus. J. Remanufacturing 1, 6. https://doi.org/10.1186/2210-4690-1-6

Gausemeier, J., Moehringer, S., 2002. VDI 2206- A New Guideline for the Design of Mechatronic Systems. IFAC Proc. Vol. 35, 785-790. https://doi.org/10.1016/S1474-6670(17)34035-1

Ghisellini, P., Cialani, C., Ulgiati, S., 2016. A review on circular economy: the expected transition to a balanced interplay of environmental and economic systems. J. Clean. Prod. 114, 11-32. https://doi.org/10.1016/j.jclepro.2015.09.007 
Hehenberger, P., Vogel-Heuser, B., Bradley, D., Eynard, B., Tomiyama, T., Achiche, S., 2016. Design, modelling, simulation and integration of cyber physical systems: Methods and applications. Comput. Ind. 82, 273-289. https://doi.org/10.1016/j.compind.2016.05.006

Kane, G.M., Bakker, C.A., Balkenende, A.R., 2018. Towards design strategies for circular medical products. Resour. Conserv. Recycl. 135, 38-47. https://doi.org/10.1016/j.resconrec.2017.07.030

Kjaer, L.L., Pigosso, D.C.A., Niero, M., Bech, N.M., McAloone, T.C., 2018. Product/Service-Systems for a Circular Economy: The Route to Decoupling Economic Growth from Resource Consumption? J. Ind. Ecol. https://doi.org/10.1111/jiec.12747

Lai, H.-H., Lin, Y.-C., Yeh, C.-H., Wei, C.-H., 2006. User-oriented design for the optimal combination on product design. Int. J. Prod. Econ. 100, 253-267. https://doi.org/10.1016/j.ijpe.2004.11.005

Lee, D.-H., In, H.P., Lee, K., Park, S., Hinchey, M., 2013. Sustainable Embedded Software Life-Cycle Planning. IEEE Softw. 30, 72-80. https://doi.org/10.1109/MS.2012.75

Mestre, A., Cooper, T., 2017. Circular Product Design. A Multiple Loops Life Cycle Design Approach for the Circular Economy. Des. J. 20, S1620-S1635. https://doi.org/10.1080/14606925.2017.1352686

Mohebbi, A., Achiche, S., Baron, L., 2018. Multi-criteria fuzzy decision support for conceptual evaluation in design of mechatronic systems: a quadrotor design case study. Res. Eng. Des. https://doi.org/10.1007/s00163-018-0287-6

Moreno, M., De los Rios, C., Rowe, Z., Charnley, F., 2016. A Conceptual Framework for Circular Design. Sustainability 8, 937. https://doi.org/10.3390/su8090937

Moulianitis, V.C., Zachiotis, G.-A.D., Aspragathos, N.A., 2018. A new index based on mechatronics abilities for the conceptual design evaluation. Mechatronics 49, 67-76. https://doi.org/10.1016/j.mechatronics.2017.11.011

Potting, J., Hekkert, M., Worrell, E., Hanemaaijer, A., n.d. Circular economy: Measuring innovation in the product chain.

Rajagopal, S., Erkoyuncu, J.A., Roy, R., 2014. Software Obsolescence in Defence. Procedia CIRP 22, 7680. https://doi.org/10.1016/j.procir.2014.07.121

Reale, F., Buttol, P., Cortesi, S., Mengarelli, M., Masoni, P., Scalbi, S., Zamagni, A., 2015. Dealing With LCA Modeling for the End Of Life of Mechatronic Products. Environ. Eng. Manag. J. 14, 16911704.

Reuter, M., Schaik, A., Ballester, M., 2018. Limits of the Circular Economy: Fairphone Modular Design Pushing the Limits.

Sandborn, P.A., 2007. Editorial Software Obsolescence-Complicating the Part and Technology Obsolescence Management Problem. IEEE Trans. Compon. Packag. Technol. 30, 886-888. https://doi.org/10.1109/TCAPT.2007.910918

Sauvé, S., Normandin, D., McDonald, M., 2016. L'économie circulaire: une transition incontournable.

SB Insight, 2018. The Nordic Market for Circular Economy: Attitudes, Behaviours \& Business Opportunities.

Schuh, G., Rudolf, S., Breunig, S., 2016. Modular Platform Design for Mechatronic Systems using Axiomatic Design and Mechatronic Function Modules. Procedia CIRP 50, 701-706. https://doi.org/10.1016/j.procir.2016.05.035

Sibalija, T.V., Majstorovic, V.D., 2012. An integrated approach to optimise parameter design of multiresponse processes based on Taguchi method and artificial intelligence. J. Intell. Manuf. 23, 15111528. https://doi.org/10.1007/s10845-010-0451-y

Sonego, M., Echeveste, M.E.S., Galvan Debarba, H., 2018. The role of modularity in sustainable design: A systematic review. J. Clean. Prod. 176, 196-209. https://doi.org/10.1016/j.jclepro.2017.12.106

Strasser, S., London, L., Kortenbout, E., 2005. Developing a Competence Framework and Evaluation Tool for Primary Care Nursing in South Africa. Educ. Health 18, 133-144. https://doi.org/10.1080/13576280500145615

Sumter, D., Bakker, C., Balkenende, A.R., 2017. The role of product designers in the transition towards the Circular Economy: A Reality Check. Presented at the Product Lifetimes And The Environment, Delft University of Technology, p. 10. 
Sundin, E., Dunbäck, O., 2013. Reverse logistics challenges in remanufacturing of automotive mechatronic devices. J. Remanufacturing 3, 2. https://doi.org/10.1186/2210-4690-3-2

Torry-Smith, J.M., Mortensen, N.H., Achiche, S., 2014. A proposal for a classification of product-related dependencies in development of mechatronic products. Res. Eng. Des. 25, 53-74. https://doi.org/10.1007/s00163-013-0161-5

Torry-Smith, J.M., Qamar, A., Achiche, S., Wikander, J., Henrik Mortensen, N., During, C., 2012. Challenges in Designing Mechatronic Systems. J. Mech. Des. 135, 011005. https://doi.org/10.1115/1.4007929

van Beek, T.J., Erden, M.S., Tomiyama, T., 2010. Modular design of mechatronic systems with function modeling. Mechatronics 20, 850-863. https://doi.org/10.1016/j.mechatronics.2010.02.002

Van den Berg, M.R., Bakker, C.A., 2015. A product design framework for a circular economy. Presented at the Product Lifetimes And The Environment, Nottingham, UK.

Villarreal-Cervantes, M.G., Cruz-Villar, C.A., Alvarez-Gallegos, J., Portilla-Flores, E.A., 2013. Robust Structure-Control Design Approach for Mechatronic Systems. IEEEASME Trans. Mechatron. 18, 1592-1601. https://doi.org/10.1109/TMECH.2012.2208196

VW Canada, 2017. Volkswagen/Audi 2.0-Litre TDI Emissions Settlement Program in Canada | [WWW Document]. URL https://www.vwcanadasettlement.ca/en/_2models (accessed 4.6.18).

Yan, J., Feng, C., 2014. Sustainable design-oriented product modularity combined with 6R concept: a case study of rotor laboratory bench. Clean Technol. Environ. Policy 16, 95-109. https://doi.org/10.1007/s10098-013-0597-3 